\title{
The Development of Polymers
}

In May 1922, Hermann Staudinger, a chemist in Germany, published a paper proposing that rubber was actually a "macromolecule," a chain of isoprene units. Other chemists raised such vocal opposition to this idea that Staudinger plunged into other intensive studies, eventually showing through examination of the viscosities of its solutions that styrene resin (which he renamed polystyrene) is also an assembly of macromolecules, giant polymers of varying lengths.

Staudinger's persistence laid the theoretical background for the entire polymer industry, which produces about 25 billion pounds of plastic each year in the Unites States alone.

A "plastic" is a polymer-based material hardened from the liquid state into one that has some degree of structural rigidity. While several polymers occur naturallysuch as shellac, rosin, and gutta-perchamost manufactured plastics begin with petroleum raw materials.

Chemist Alexander Parkes created the first plastic, Parkesine (later called xylonite), in England in 1862. Parkes began with cellulose nitrate, which he obtained by treating cotton linters (the short fibers left over after ginning, which removes the long staple fibers) in a mixture of nitric acid and sulfuric acid. Wood pulp treated with alkali also provides another natural source of cellulose (itself a natural polymer made of glucose units). Parkes softened his nitrocellulose with vegetable oils and a small amount of camphor, which yielded a crude plastic material.

Six years after Parkes' discovery, John W. Hyatt in the United States recognized the importance of adding camphor to cellulose nitrate. Mixing the cellulose nitrate with alcohol and camphor yields a plastic mass that can be rolled into sheets, pressed into a block, and then dried and polished to the required form. Hyatt molded the new plastic material into billiard balls, combs, detachable collars, and other articles. Originally considered the best substitute for ivory and tortoiseshell, this material found substantial early uses in carriage and automobile windshields.

The same plastic, called celluloid, was introduced as a photographic film base in 1884 by the Eastman-Kodak Company (see Historical Note in the June 1989 MRS Bulletin). Cellulose treated with acetic acid, called cellulose acetate, was a clear, tough material, also used over the next several decades as a photographic film base. Cellulose triacetate, which is soluble in toxic solvents, was used as a waterproof varnish for the fabric on airplane wings. Transparent acetate film also became popular for packaging.

The first completely synthetic polymer resin was patented in the United States in 1909 by Leo Hendrik Baekeland. He named his hardened amberlike material, produced from phenol and formaldehyde, "Bakelite." (See Historical Note in the July 1989 MRS Bulletin.)

\section{High-density polyethylene made its first public appearance in the form of hula hoops.}

In 1835 the reaction of acetylene with hydrochloric acid was found to produce vinyl chloride, but not until 1912 was this polymerized into polyvinyl chloride. Similarly, methacrylate was discovered about the same time but was not polymerized in the laboratory until 1880 , and not put into commercial production as polymethyl methacrylate until 1927. Much of the work done in Germany, including similar attempts to convert styrene into polystyrene, can be traced to that country's efforts to become independent from other European chemical industries. Polyvinyl chloride and polystyrene are now two of the most widely produced plastics in the world.

After seven years of work, a research team lead by Wallace $\mathrm{H}$. Carothers at $\mathrm{Du}$ Pont discovered a new material called "superpolyamide," later known as nylon, in 1935. The knowledge these researchers gained in synthesizing polymers and polymer fibers had a great effect on subsequent plastics research. (See Historical Note in the May 1988 MRS Bulletin.)

One of the most important plastics, polyethylene, first came into commercial production in 1939. The polymerization of ethylene was made possible by the development of high-pressure technology, as discovered in 1934 by a team led by E.W. Fawcett and R.O. Gibson at Britain's Imperial Chemical Industries. Their process used oxygen as a catalyst, with ethylene at temperatures around $200^{\circ} \mathrm{C}$ and at pressures above 1,500 pounds per square inch. Fawcett and Gibson's form of polyethylene, low-density polyethylene or LDPE, was white and waxy. Polyethylene is resistant to all aqueous solutions and organic solvents at temperatures below $50^{\circ} \mathrm{C}$. It ranks first in commercial production of plastics, with about five billion pounds produced annually in the United States alone. Originally, LDPE had unique value in radar applications, but is now widely used in injection molding.

In 1945, Earl S. Tupper founded the Tupper Plastics Company and began using polyethylene to make household storage, freezing, and serving containers (though he called the material "Poly- $T$ " instead of polyethylene). At first, the public did not understand the benefits of the virtually airtight and liquid-tight seals made possible through plastics, or of the benefits of polyethylene containers over those of glass or tin. So Tupper established the new technique of home demonstrations to sell his "Tupperware" products.

In the early 1950s, Karl Ziegler, working at the Max-Planck-Institut in West Germany, developed organometallic catalysts that allowed polymerization of ethylene at room pressures and at a temperature of only $60^{\circ} \mathrm{C}$. Ziegler's type of polyethylene, much more rigid and harder than LDPE, is called high-density polyethylene, or HDPE. HDPE is used for large drums, gasoline tanks, bottle crates, and domestic appliance moldings, but it made its first public appearance in the form of hula hoops.

In the mid-1950s, Giulio Natta, working at the Polytechnic Institute in Milan, Italy, discovered how Ziegler's organometallic catalysts could also be used to polymerize propylene. Polypropylene is a rigid plastic material that can withstand boiling water and can be molded with a glossy finish. With its excellent resistance to solvents and aqueous solutions, polypropylene is commonly used for automobile ducts, washing machine agitators, and foamed furniture parts.

The work of Ziegler and Natta led to many new types of plastics. To date, specialized polymers have been developed for virtually every type of application, including extremely specialized materials for high-tech industries, chemical-protective clothing, and the space program.

KEVIN J. ANDERSON 